\title{
Integration of Scheimpflug-Based Corneal Tomography and Biomechanical Assessments for Enhancing Ectasia Detection
}

\author{
Renato Ambrósio, Jr., MD, PhD; Bernardo T. Lopes, MD; Fernando Faria-Correia, MD; \\ Marcella Q. Salomão, MD; Jens Bühren, MD; Cynthia J. Roberts, PhD; Ahmed Elsheikh, PhD; \\ Riccardo Vinciguerra, MD; Paolo Vinciguerra, MD
}

\begin{abstract}
PURPOSE: To present the Tomographic and Biomechanical Index (TBI), which combines Scheimpflugbased corneal tomography and biomechanics for enhancing ectasia detection.
\end{abstract}

METHODS: Patients from different continents were retrospectively studied. The normal group included 1 eye randomly selected from 480 patients with normal corneas and the keratoconus group included 1 eye randomly selected from 204 patients with keratoconus. There were two groups: 72 ectatic eyes with no surgery from 94 patients with very asymmetric ectasia (VAE-E group) and the fellow eyes of these patients with normal topography (VAE-NT group). Pentacam HR and Corvis ST (Oculus Optikgeräte $\mathrm{GmbH}$, Wetzlar, Germany) parameters were analyzed and combined using different artificial intelligence methods. The accuracies for detecting ectasia of the Belin/Ambrósio Deviation (BAD-D) and Corvis Biomechanical Index (CBI) were compared to the $\mathrm{TBI}$, considering the areas under receiver operating characteristic curves (AUROCs).

RESULTS: The random forest method with leave-oneout cross-validation (RF/LOOCV) provided the best artificial intelligence model. The AUROC for detecting ectasia (keratoconus, VAE-E, and VAE-NT groups) of the TBI was 0.996, which was statistically higher (DeLong et al., $P$ $<.001)$ than the BAD-D (0.956) and CBI (0.936). The TBI cut-off value of 0.79 provided $100 \%$ sensitivity for detecting clinical ectasia (keratoconus and VAE-E groups) with $100 \%$ specificity. The AUROCs for the TBI, BAD-D, and $\mathrm{CBI}$ were $0.985,0.839$, and 0.822 in the VAE-NT group (DeLong et al., $P<.001$ ). An optimized TBI cut-off value of 0.29 provided $90.4 \%$ sensitivity with $96 \%$ specificity in the VAE-NT group.

CONCLUSIONS: The TBI generated by the RF/LOOCV provided greater accuracy for detecting ectasia than other techniques. The TBI was sensitive for detecting subclinical (fruste) ectasia among eyes with normal topography in very asymmetric patients. The TBI may also confirm unilateral ectasia, potentially characterizing the inherent ectasia susceptibility of the cornea, which should be the subject of future studies.

[J Refract Surg. 2017;33(7):434-443.]

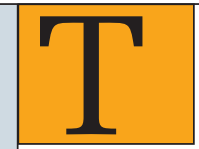

he detection of mild or subclinical forms of ectatic corneal diseases has gained relevance because these cases are at high risk for developing iatrogenic progressive ectasia (keratectasia) after corneal laser vision correction. ${ }^{1,2}$ Ectasia progression occurs due to the biomechanical decompensation of the corneal stroma, which is related to the preoperative predisposition or biomechanical status of the cornea and to the structural impact from the surgical procedure itself and after surgery. The impact from the procedure may be evaluated using parameters such as the residual stromal bed and the percent of tissue altered..$^{3-6}$ The current concept is that screening for ectasia risk involves understanding the inherent ectasia susceptibility of the cornea, which is

From Rio de Janeiro Corneal Tomography and Biomechanics Study Group, Rio de Janeiro, Brazil (RA, BTL, FF-C, MQS); the Department of Ophthalmology, Federal University of São Paulo, São Paulo, Brazil (RA, BTL, MQS); the Department of Ophthalmology, Pontific Catholic University of Rio de Janeiro, Rio de Janeiro, Brazil (RA); the School of Health Sciences, University of Minho, Braga, Portugal (FF-C); Augenpraxisklinik Triangulum; Hanau, Germany (JB); the Departments of Ophthalmology \& Visual Science and Biomedical Engineering, Ohio State University, Columbus, Ohio (CJR); the School of Engineering, University of Liverpool, Liverpool, United Kingdom (AE); the Department of Surgical Sciences, Division of Ophthalmology, University of Insubria, Varese, Italy (RV); the Department of Corneal and External Eye Diseases, St. Paul's Eye Unit, Royal Liverpool University Hospital, Liverpool, United Kingdom (RV); the Eye Center, Humanitas Clinical and Research Center, Rozzano, Italy (PV); and Vincieye Clinic, Milan, Italy (PV).

Submitted: November 3, 2016; Accepted: April 11, 2017

(C) 2017 Ambrósio, Lopes, Faria-Correia, et al.; licensee SLACK Incorporated. This is an Open Access article distributed under the terms of the Creative Commons Attribution 4.0 International (https://creativecommons.org/licenses/by/4.0). This license allows users to copy and distribute, to remix, transform, and build upon the article, for any purpose, even commercially, provided the author is attributed and is not represented as endorsing the use made of the work.

Dr. Ambrósio, Dr. P. Vinciguerra, and Dr. Roberts are consultants for, Dr. Bühren has received lecture fees from, and Dr. Elsheikh has received research funding from Oculus Optikgeräte GmbH (Wetzlar, Germany). The remaining authors have no financial or proprietary interest in the materials presented herein.

The authors thank Dr. Sven Reisdorf and Andreas Steinmuller (Oculus Optikgeräte $\mathrm{GmbH}$ ) for helpful discussions and calculations. The Corvis ST instruments used in this study were provided by Oculus Optikgeräte GmbH.

Correspondence: Renato Ambrósio, Jr., MD, PhD, Rua Conde de Bonfim 211/712-Rio de Janerio, RJ-20.520-050, Brazil. E-mail: dr.renatoambrosio@ gmail.com

doi:10.3928/1081597X-20170426-02 
not limited to the detection of mild cases with ectatic corneal disease. ${ }^{2}$ Besides elective refractive surgery, identifying mild ectasia and monitoring disease progression have become of utmost importance because of the paradigm shift related to the introduction of novel treatments for ectatic corneal disease, including corneal cross-linking (CXL) and intrastromal corneal ring segments. ${ }^{7,8}$

Beyond shape analysis, clinical biomechanical assessment has been expected for enhancing the overall accuracy for identifying mild forms of ectatic corneal disease. ${ }^{9,10}$ In fact, the concept for ectasia pathophysiology as proposed by Roberts and Dupps ${ }^{11}$ is that a focal abnormality in corneal biomechanical properties precipitates a cycle of decompensation, leading to secondary localized thinning and steepening (bulging), generating optical aberrations.

The Corvis ST (Oculus Optikgeräte GmbH, Wetzlar, Germany) is also a non-contact tonometer with a collimated air pulse with fixed pressure that uses an ultra high-speed Scheimpflug camera to monitor corneal deformation. ${ }^{12-14}$ The first set of parameters derived from the Corvis ST measurement had relatively low accuracy for keratoconus. ${ }^{15-18}$ However, new parameters including the inverse concave radius of curvature during the concave phase of the deformation response, the deformation amplitude ratio between the apex and at $2 \mathrm{~mm}$ from the apex, the stiffness parameter at first applanation, ${ }^{14,18}$ and the horizontal thickness profile ${ }^{19}$ were combined by linear regression analysis for the development of the Corneal Biomechanical Index (CBI), which provides high accuracy to detect keratoconus. ${ }^{20}$ In addition to the detection of ectatic corneal disease, the characterization of the deformation response has also provided an equation for intraocular pressure correction, reducing reliance of intraocular pressure measurements on both corneal thickness and age. ${ }^{21}$

The purpose of the current study was to develop a combined parameter based on Scheimpflug imaging to advance the ability to detect clinical and subclinical ectasia using corneal tomography data from the Pentacam (Oculus Optikgeräte $\mathrm{GmbH})^{22}$ and biomechanical assessment from the Corvis ST.

\section{PATIENTS AND METHODS}

Eight hundred fifty eyes from 778 patients were included in this multicenter retrospective study. The patients were enrolled from two clinics located on two different continents: Instituto de Olhos Renato Ambrósio in Rio de Janeiro, Brazil, and the Vincieye Clinic in Milan, Italy. The institutional review board from Humanitas Clinical and Research Center (Milan, Italy) ruled that approval was not required for the retrospective chart review study. The ethics committee of the Federal University of São Paulo approved this retrospective research study, which was conducted in accordance with the tenets of the 1964 Declaration of Helsinki (revised in 2000).

The eyes were divided into four groups. The normal group included one eye randomly selected from 480 patients with normal corneas. The keratoconus group included one eye randomly selected from 204 patients with keratoconus; one eye was randomly included per patient to avoid selection bias related to the use of both eyes from the same patient. ${ }^{23}$ The VAE-E group included 72 eyes from 94 patients with very asymmetric ectasia that had no surgery and the VAE-NT group included the fellow eyes of these patients that had normal topography. Twenty-two of 94 very asymmetric ectasia cases had one or more surgical procedures (eg, CXL or intracorneal ring segments implantation) in the ectatic eye prior to the study and were not included in the VAE-E group because these cases did not have a Corvis ST measurement preoperatively.

All patients had a comprehensive ophthalmic examination, including the Corvis ST and Pentacam HR examinations with acceptable quality for proper analysis. Soft contact lens wear was discontinued for at least 3 days prior to the examination and rigid or hybrid contact lenses were discontinued for a minimum period of 3 weeks. The inclusion criteria for being a normal case was to have normal corneas on the general eye examination in both eyes, including normal slitlamp biomicroscopy, corrected distance visual acuity of 20/20 or better, overall subjective normal topography and tomography examinations with no previous surgery, and no use of topical medications other than artificial tears in both eyes. The criterion for keratoconus was the diagnosis of clinical ectasia in both eyes without any previous ocular procedures (eg, CXL or intracorneal ring segments implantation). ${ }^{8,24}$ The criteria for clinical diagnosis of ectasia included topographic characteristics (eg, skewed asymmetric bowtie or inferior steepening) and at least one slit-lamp finding (eg, Munson's sign, Vogt's striae, Fleischer's ring, apical thinning, or Rizutti's sign). ${ }^{24}$ Patients were considered to be very asymmetric if the diagnosis of ectasia was confirmed in one eye based on the previously described criteria and the fellow eye had a normal front surface curvature (topometric) map. Objective criteria for considering normal topography was rigorously applied for defining the cases of VAE-NT, including objective front surface curvature metrics derived from Pentacam, such as a keratoconus percentage index (KISA\%) score lower than 60 and a paracentral inferior-superior (I-S value) asymmetry value at $6 \mathrm{~mm}$ (3-mm radii) less than $1.45 .{ }^{25}$ These criteria avoid prob- 
lems related to the subjectivity and inter-examiner and intra-examiner variability of the classifications of topographic maps. ${ }^{26}$ All cases from each clinic had the tomographic data masked for reevaluation by an anterior segment expert from the other center (RA and PV) for confirming inclusion criteria. Interestingly, the Belin/ Ambrósio Enhanced Ectasia Display was not considered part of the classification criteria.

All measurements from the Corvis ST and Pentacam HR were taken by experienced technicians using the same software and hardware at each center. Proper examination quality was ensured by a manual, frame-byframe analysis of each examination by an independent masked examiner to ensure quality of each acquisition, including good edge detection over the whole deformation response or rotating Scheimpflug images, with the exclusion of severe alignment errors (x-direction) and blinking errors. Data from the Pentacam HR and Corvis ST were exported to a custom spreadsheet using research software, which is currently available on the instrument.

\section{Statistical ANALYSIS}

Statistical analyses were performed by different software packages: MedCalc Statistical Software (version 16.8.4; MedCalc; Ostend, Belgium; https://www.medcalc.org), SPSS (version 23; IBM Corporation, Armonk, NY), the R Core Team (version 3.3.1.2016; R Foundation for Statistical Computing, Vienna, Austria; https:// www.R-project.org/), and a custom-written MATLAB program (R14; The MathWorks, Natick, MA).

The data were analyzed and combined using different artificial intelligence methods, including logistic regression analysis with forward stepwise inclusion, support vector machine, and random forest. ${ }^{23,27}$ These methods were employed to optimize the ability to distinguish normal corneas (normal group) from ectatic cases (keratoconus, VAE-E, and VAE-NT groups) by the combination of parameters from corneal deformation response and tomography, including the $\mathrm{CBI}^{20}$ and Belin/Ambrósio Deviation (BAD-D). ${ }^{9,10,18,22,28-31}$ Considering the combined parameters were programmed to have their output values as a continuous number ranging from 0 to 1 , a linear regression analysis function was created using only the BAD-D as the input parameter to calculate the Belin/Ambrósio Deviation normalized index (BAD-DI) to facilitate comparisons.

The leave-one-out cross-validation (LOOCV) technique was chosen for validation. In this method, a new model is built as many times as the number of cases included in the study. Each different model is built for all cases, excluding one patient in whom the model is tested. The results of the cases not included in each of the 850 built models provide the output values of the LOOCV. Therefore, the validation model refers to the different models that were built with the LOOCV strategy. Considering the number of false-positive and false-negative cases, the model is validated or not. Once the model is properly validated for its generalized performance, a definitive algorithm would be built for all cases, which is expected to provide a more optimistic performance, but possibly with some degree of overfitting. However, it is expected that the results from the LOOCV provide a more realistic estimation of the performance when the model is applied in a novel population.

The Kolmogorov-Smirnov goodness-of-fit test and D’Agostino-Pearson test were applied for checking normal distributions. The Spearman rank correlation test was used to measure the degree of association between age and the Tomographic and Biomechanical Index (TBI). Analysis of variance (ANOVA) was used to test differences for age among the groups. Considering all indices in the keratoconus group were nonnormally distributed, the analyzed parameters were compared among the groups using the non-parametric Kruskal-Wallis test, followed by the post hoc Dunn's test to compare each pair of groups. The discriminative ability of each parameter was assessed by receiver operating characteristic (ROC) curves. For each parameter tested, the area under the ROC curve (AUROC) was calculated and the best cut-off value that yielded the highest accuracy was determined along with the sensitivity and specificity. Pairwise comparisons of the AUROC were accomplished with the non-parametric approach as described by DeLong et al. for comparing the performance of diagnostic tests. ${ }^{32}$ Furthermore, separation curves that display accuracy as a function of shifting the cut-off value were plotted as described by Bühren et al. ${ }^{33}$ This method allows for comparisons among the different metrics by using normalized cutoff points by a Z transformation with the optimum cut-off value set to zero. The area under the separation curve (AUSEP) was calculated between the $\mathrm{x}$ limits of -2 and 2 standard deviations and y limits of $50 \%$ and $100 \%$ accuracy. Thus, higher AUSEP values indicate a high discriminative ability with a high tolerance to shifts of the critical cut-off value. ${ }^{33}$ For ROC analysis, a custom-written MATLAB program was used to confirm results obtained by MedCalc.

\section{RESULTS}

A total of 364 patients (227 normal, 111 with keratoconus, and 26 with very asymmetric ectasia) were enrolled from the Rio de Janeiro Corneal Tomography and Biomechanics Study Group at Instituto de Olhos Renato Ambrósio in Rio de Janeiro, Brazil. Four hun- 


\begin{tabular}{|c|c|c|c|c|c|c|c|c|}
\hline \multirow[b]{3}{*}{ Group } & \multicolumn{7}{|c|}{$\begin{array}{c}\text { TABLE } 1 \\
\text { Demographic Characteristics }\end{array}$} & \\
\hline & \multicolumn{4}{|c|}{ Rio de Janeiro } & \multicolumn{4}{|c|}{ Milan } \\
\hline & No. & Male & Female & Average Age (y) (Range) & No. & Male & Female & Average Age (y) (Range) \\
\hline Normal & 227 & 96 & 131 & 37.71 (7 to 90$)$ & 253 & 108 & 145 & 43.20 (7 to 88$)$ \\
\hline KC & 111 & 72 & 39 & 32.90 (12 to 64$)$ & 93 & 66 & 27 & 38.10 (16 to 72$)$ \\
\hline VAE-E & 19 & 10 & 9 & 32.89 (14 to 74$)$ & 53 & 30 & 23 & 36.96 (13 to 83 ) \\
\hline VAE-NT & 26 & 15 & 11 & 35.02 (14 to 74$)$ & 68 & 39 & 29 & 37.66 (13 to 83 ) \\
\hline
\end{tabular}

dred fourteen patients were enrolled from the Vincieye Clinic in Milan, Italy (253 normal, 93 with keratoconus, and 68 with very asymmetric ectasia). Table 1 summarizes the demographic characteristics of the groups. Females accounted for $57.5 \%$ of normal patients, whereas $64.43 \%$ of the patients with ectasia were male. There were no statistically significant differences for age among the groups (ANOVA, $P=.273$ ). However, there was a broader range in the normal group.

Table A (available in the online version of this article) summarizes the descriptive statistics of the most important parameters among the groups. Central and minimal corneal thickness values and maximum (Kmax) keratometric values were normally distributed among normal eyes $(P>.50)$. Central (apex) thickness averaged $558 \pm$ $30.1 \mu \mathrm{m}$ (range: 470 to $674 \mu \mathrm{m}$ ). Mean thinnest corneal thickness was $552 \pm 30 \mu \mathrm{m}$ (range: 467 to $646 \mu \mathrm{m}$ ). The average difference between central and thinnest point values was $5.8 \pm 4 \mu \mathrm{m}$ (range: 0 to $24 \mu \mathrm{m}$ ) with $10.4 \%$ of cases having a greater than $10 \mu \mathrm{m}$ difference and $3.1 \%$ having a greater than $15 \mu \mathrm{m}$ difference. The mean Kmax value was $44.38 \pm 1.54$ diopters (D) (range: 40.2 to 48.5 D). Eighteen eyes $(3.75 \%)$ in the normal group had a positive topometric keratoconus classification. ${ }^{34}$ In addition, six cases $(1.25 \%)$ from the normal group had an I-S value higher than 1.45 and 1 case $(0.21 \%)$ had a KISA\% score higher than 60 . The mean BAD-D score was $0.745 \pm 0.56$ (range: -1.13 to 2.35 ). Twenty eyes from the normal group (4.6\%) had BAD-D values higher than 1.6 and 82 eyes (17.1\%) had BAD-D values higher than 1.26 among normal eyes. The CBI score was higher than 0.5 in $2.5 \%$ of normal cases (false-positive results).

All frank ectasia cases (keratoconus and VAE-E groups) had abnormalities detected by corneal topography that fulfilled criteria for diagnosis. ${ }^{24,25}$ However, 48 cases (17.4\%) had Kmax values lower than 47.50 D and 23 cases (8.7\%) had Kmax values lower than 46.00 D. The Oculus topometric classification for keratoconus ${ }^{34}$ distribution was negative for 13 cases (4.7\%). According to the Oculus topometric classification for keratoconus, 89 cases $(32.2 \%)$ were classified as grade 1, $78(28.3 \%)$ as grade 2, $67(24.3 \%)$ as grade 3, and $29(10.5 \%)$ as grade 4 ectasia. Four frank ectatic cases $(1.4 \%)$ had a BAD-D score lower than 1.6, 14 cases (5.1\%) had an I-S value lower than $1.45 \mathrm{D}$, and 40 cases $(14.5 \%)$ had a KISA\% score lower than 60 . The CBI score was higher than 0.5 in $94.2 \%$ of frank ectatic eyes.

All eyes in the VAE-NT group were objectively determined to have normal topography, an I-S value lower than 1.45 D, a KISA\% score lower than 60, and no positive topometric classification for keratoconus value. ${ }^{25}$ Figure 1 displays the front surface axial or sagittal curvature (topometric) maps using the Smolek-Klyce absolute $1.50 \mathrm{D}$ scale from the 94 patients in the VAENT group. The BAD-D score was higher than 1.6 in 40 cases $(42.6 \%)$ and higher than 1.26 in 64 cases $(68.1 \%)$. Thirty-five $(37.2 \%)$ cases in the VAE-NT group had a CBI score higher than 0.5 and 42 cases (44.7\%) had a CBI score higher than 0.3 .

Three different artificial intelligence approaches were applied for combining data from corneal deformation response (Corvis ST) and corneal tomography (Pentacam) data using LOOCV. Indices were determined from the logistic regression analysis with forward stepwise inclusion, support vector machine, and random forest. The most accurate method was the random forest, which is referred to as the TBI. A linear regression formula was applied for normalizing the BAD-D into an index, with outputs ranging from 0 to 1 (BAD-DI). The BAD-DI formula included a constant and a coefficient for BAD-D ( $\mathrm{y}=\mathrm{a}+$ $\left.b^{*} \mathrm{x}\right): 2.85958$ (constant) $+(-4.84877$ * BAD-D), so that the BAD-D and BAD-DI had a perfect correlation. However, this approach facilitates comparison with other parameters as seen in Figure 2, which displays the dot plot graphs for the BAD-D, BAD-DI, CBI, and TBI.

Table A includes the mean \pm standard deviation, median, and range (minimum to maximum) for the main parameters, including the BAD-D, BAD-DI, CBI, linear regression analysis, support vector machine, and TBI. Results of Kruskal-Wallis one-way ANOVA demonstrated differences among the studied groups for all studied parameters $(P<.000001)$, which was confirmed 


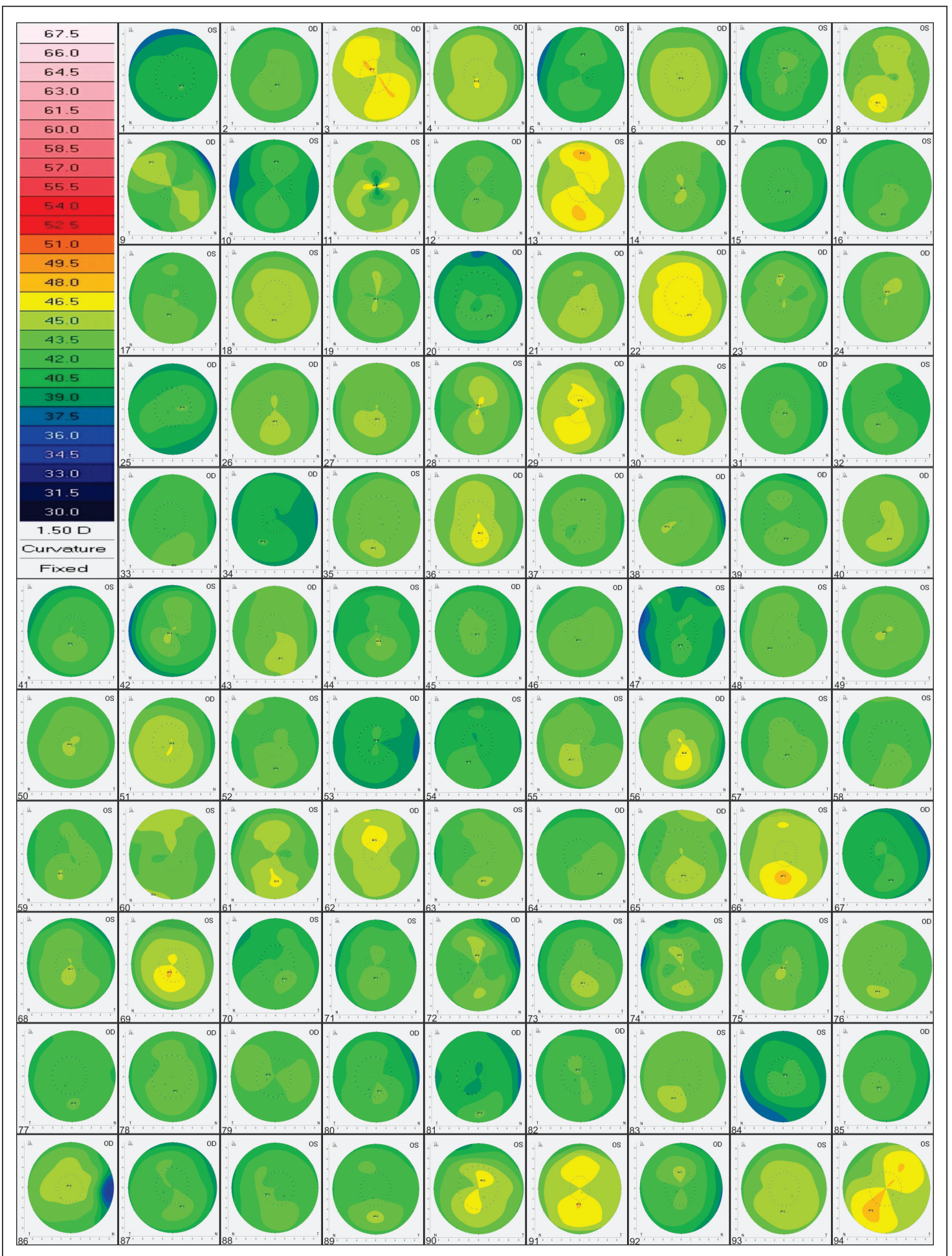

Figure 1. Front surface axial or sagittal curvature (topometric) maps using the Smolek-Klyce absolute 1.50 diopters (D) scale from the 94 cases in the very asymmetric ectasia with normal topography (VAE-NT) group.

by Jonckheere-Terpstra trend test $(P<.00001)$. Post hoc Dunn's test results were similar for all parameters, confirming differences among all paired groups $(P<$ .001), with the exception of the comparison between keratoconic and ectatic eyes from the very asymmetric cases (keratoconus group $\times$ VAE-E group).
Table B (available in the online version of this article) summarizes the results of ROC curve analysis and AUSEP calculated between the limits of -2 and +2 standard deviations. The analysis was performed for testing the discriminating abilities to separate normal cases and all diseased cases, normal cases from the cases 


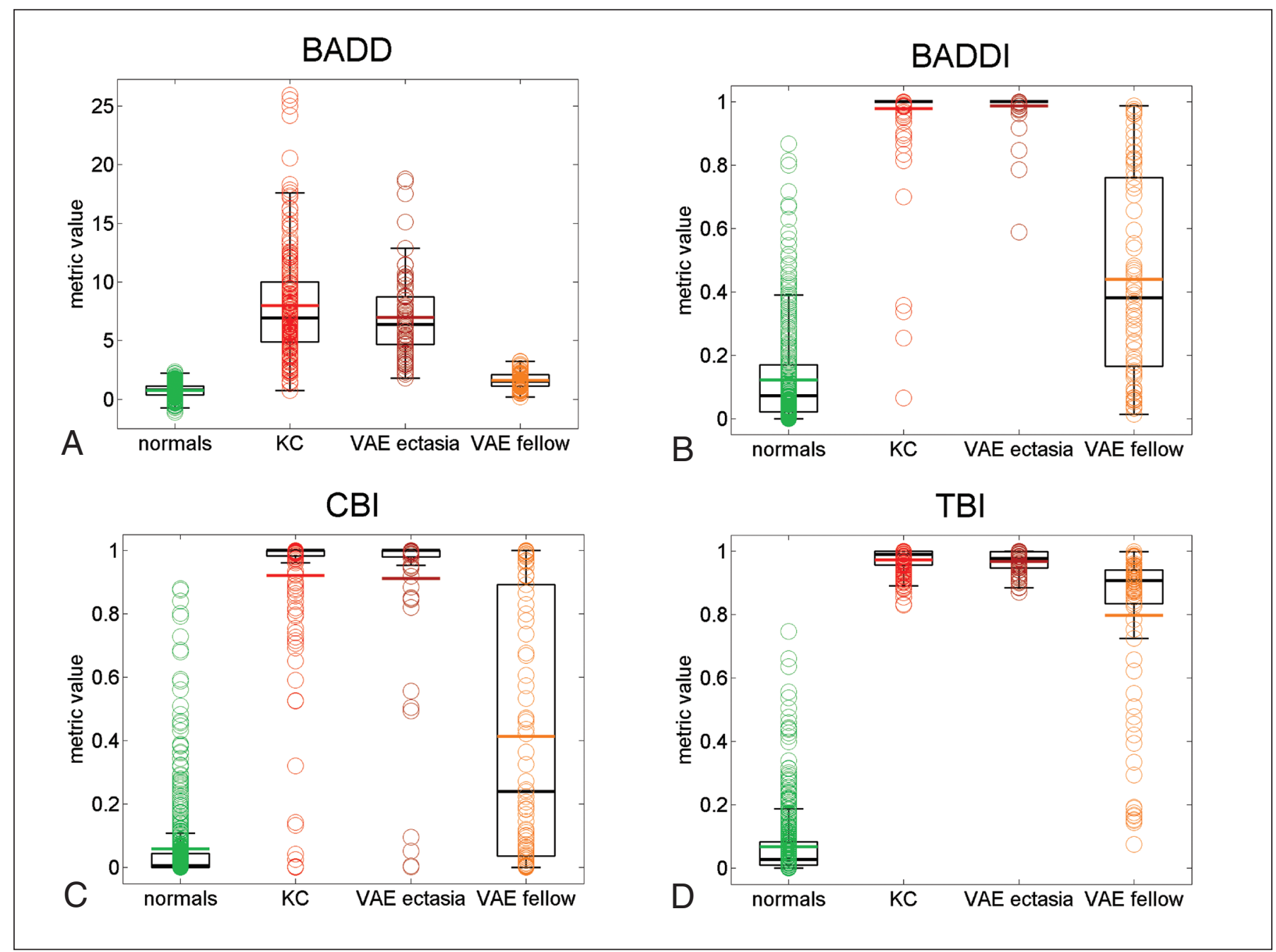

Figure 2. Box and dot plots showing the distribution of metric values across the normal $(n=480)$, keratoconus $(K C)(n=204)$, very asymmetric ectasia with clinical ectasia (VAE-E) $(n=72)$, and very asymmetric ectasia with normal topography (VAE-NT) $(n=94)$ groups. (A) Belin/Ambrósio Deviation (BAD-D); (B) Belin/Ambrósio Deviation normalized index (BAD-DI); (C) Corvis Biomechanical Index (CBI); and the Tomographic and Biomechanical Index $(\mathrm{TBI})$. The box spans the first and third quartile. The whiskers indicate the 1.5-fold interquartile range. Colored markers representing each value in each patient and its mean are superimposed.

with frank ectasia, and normal cases with the supposed subclinical cases. These data correlate to Figure 3.

The TBI results presented refer to the outputs of the random forest method with LOOCV strategy, which provided the highest accuracy compared to linear regression analysis and support vector machine. The AUROC of the TBI for detecting ectasia (keratoconus, VAE-E, and VAE-NT groups) was 0.996. The cut-off value of 0.48 correctly classified $97.5 \%$ of the cases, having $98.8 \%$ specificity with $96.2 \%$ sensitivity. The TBI had $100 \%$ sensitivity to detect frank ectasia cases (AUROC = 1.0; keratoconus and VAE-E groups) with no false-positive results among the normal cases and optimal cut-off values ranging from 0.75 to 0.81 . Considering the ability to detect the eyes with normal topography from patients with clinical ectasia in the fellow eye, an optimization of cut-off value to 0.29 provided $90.4 \%$ sensitivity with $4 \%$ false-positive results $(96 \%$ specificity; AUROC $=0.985)$. The TBI had a statistically higher AUROC (DeLong et al., $P<$ .001) than all other parameters for every analysis performed, except for the comparisons with the BAD-D for detecting clinical ectasia cases (keratoconus and VAE-E groups), in which the AUROC was 1.0 for the TBI and 0.997 for the the BAD-D and BAD-DI (DeLong et al., $P=.1198)$. However, the AUSEPs for the BAD-D and BAD-DI were 64 and 95, respectively, whereas it was 112 for the TBI. Such a difference in the AUSEP potentially confirms the higher discriminating ability of the TBI compared to the BAD-D to distinguish normal and clinical ectatic cases despite the non-significant differences found among the AUROCs (Table B). 
A

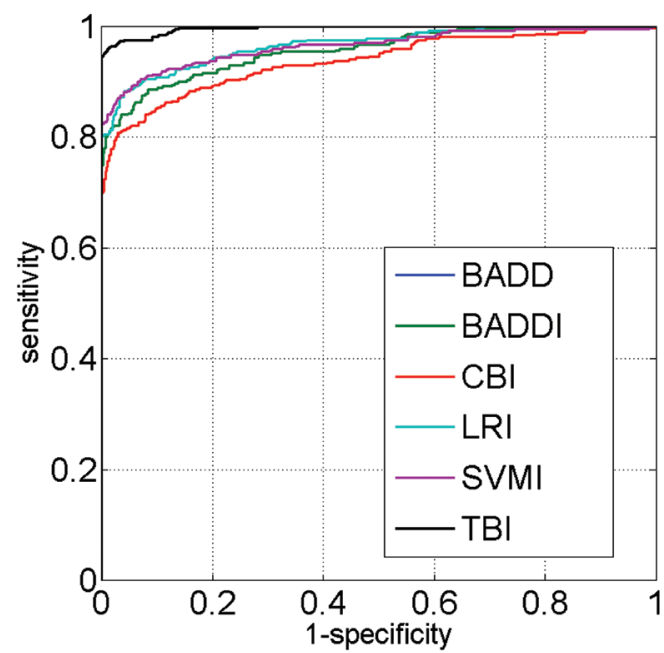

B
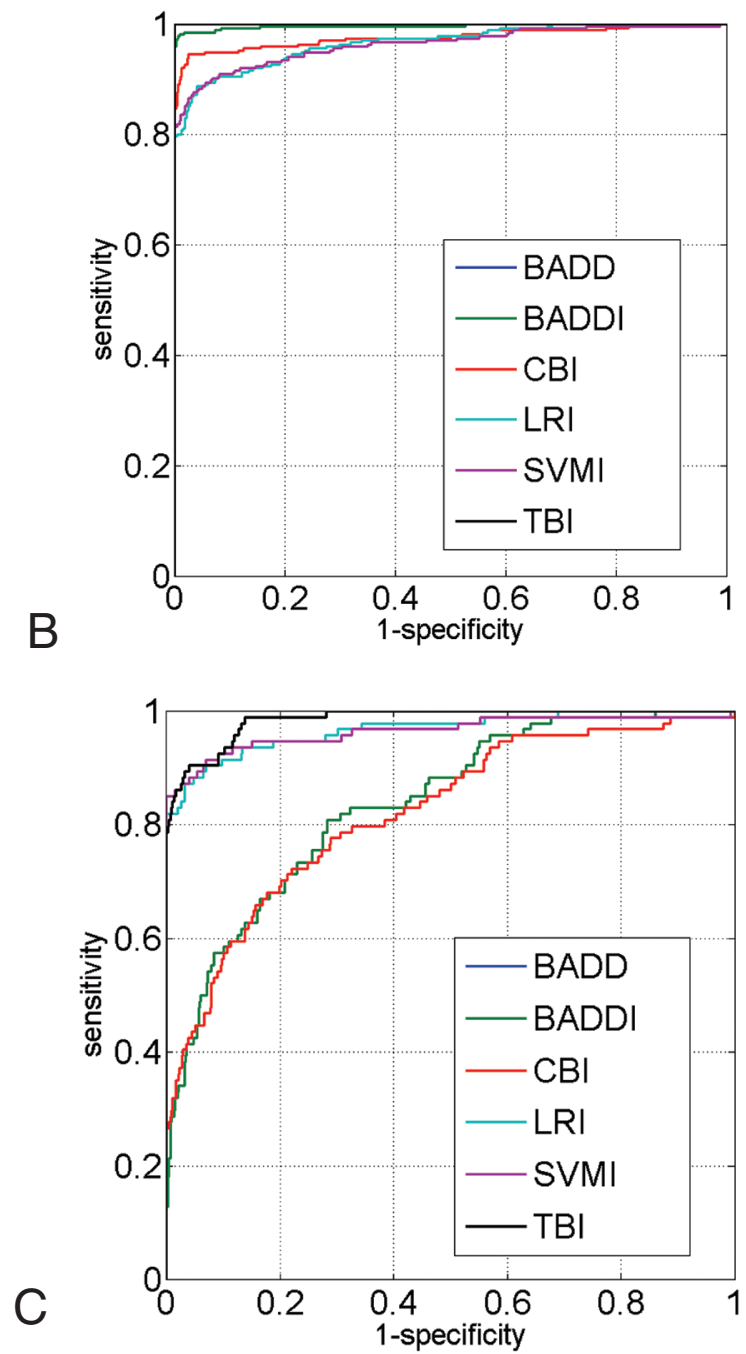
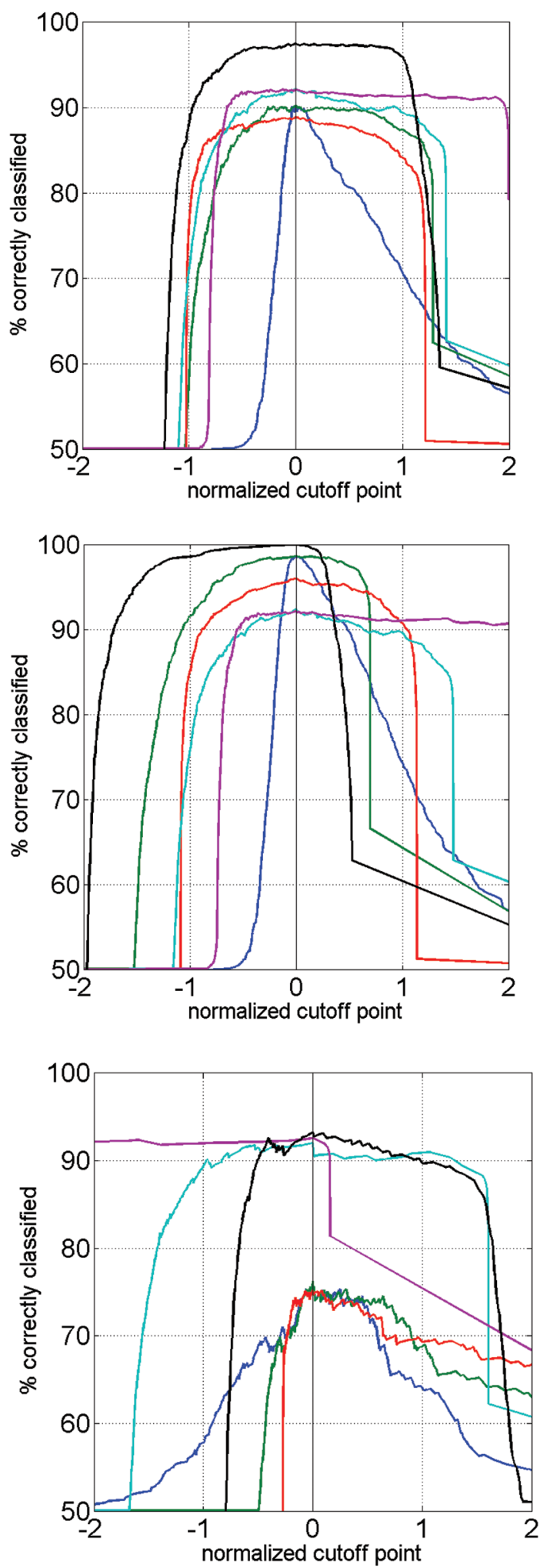

Figure 3. Receiver operating characteristic and separation curves for the different groups. (A) Normal vs keratoconus, very asymmetric ectasia with clinical ectasia (VAE-E), and very asymmetric ectasia with normal topography (VAE-NT) groups; (B) normal vs keratoconus and VAE-E groups; and (C) normal vs VAE-NT groups. BAD-D = Belin/Ambrósio Deviation; BAD-DI = Belin/Ambrósio Deviation normalized index (BAD-DI); CBI = Corvis Biomechanical Index; LRI = linear regression analysis index; SVMI = support vector machine; $\mathrm{TBI}=$ Tomographic and Biomechanical Index 
The TBI had a significant negative correlation with age $(P<.0001$; Spearman's coefficient of rank correlation $[\mathrm{rho}]=-0.18)$.

The 'final' random forest algorithm that is programmed and included in the commercial Oculus software is based on an optimized algorithm that included all 850 cases in the training set. This output provided an effectively perfect accuracy, reaching an AUROC of 1.0 for all subgroup comparisons in the current study. Considering the highest value for normal cases was 0.34 and the lowest values for frank ectatic cases (keratoconus and VAE-E groups) and VAE-NT cases were 0.91 and 0.37 , respectively. The cut-off value of 0.35 correctly classified $100 \%$ of the cases. Interestingly, the correlation of the output of the TBI with the random forest/LOOCV output and the final model was highly significant $(P<.0001$; Spearman's coefficient of rank correlation $[\mathrm{rho}]=0.887$ ).

\section{DISCUSSION}

In this study, we introduce the TBI as a novel parameter based on a robust and innovative combination of data derived from Scheimpflug-based corneal tomographic and biomechanical analysis. The TBI is derived from Pentacam HR and Corvis ST examinations, resulting in higher accuracy for detecting ectatic corneal diseases than all previous analyzed parameters. This was confirmed by analyzing the AUROC and AUSEP (Figures 2-3). Although it is important to include cases with mild or subclinical forms of ectatic corneal disease to facilitate appreciation of the clinical benefit for the novel parameter, the AUROC of the TBI was statistically higher than all other analyzed parameters, including the CBI, when considering the detection of cases with clinical ectasia (keratoconus and VAE-E groups). As demonstrated by Vinciguerra et al. ${ }^{20}$ the CBI was accurate for detecting clinical ectasia cases, with 16 false-negative cases (5.7\%) and 97.5\% specificity, and an AUROC of 0.977, which was statistically lower than the TBI. In addition, the AUSEP potentially reveals the benefits of the TBI over metrics that are highly accurate. For example, the BAD-D ${ }^{9,10,18,22,28-31}$ had $98.2 \%$ sensitivity to detect clinical ectasia with less than $1 \%$ false-positive results (99.2\% specificity) among normal eyes in the current study. The AUROC of the BAD-D (and BAD-DI) was 0.997, which is not significantly lower than that for the TBI (1.0) according to DeLong et al.'s test to compare AUROCs. ${ }^{32}$ However, the AUSEP as described by Bühren et al. ${ }^{33}$ discloses a more dichotomous response characteristic of the TBI (Figure 2D), which is more tolerant to shifts on the cut-off criterion compared to the BAD$\mathrm{D}$ and BAD-DI (Figure 2A).

The study included a large cohort of patients with normal corneas and with different levels of ectatic corneal disease. To avoid selection bias related to the use of both eyes from the same patient, we included one eye randomly selected per patient in the normal and keratoconus groups. ${ }^{23}$ Seventy-two patients had one eye assigned to the VAE-E group and the other eye to the VAE-NT group. Although these patients had both eyes included, these cases were by definition very asymmetric, which avoids the problems related to enantiomorphism or similarities between right and left eyes. Considering the limitations of subjective interpretation of corneal topography maps, ${ }^{26}$ we were restricted to applying front surface curvature indices as described by Rabinowitz and Rasheed ${ }^{25}$ for objectively defining the inclusion criteria of the VAENT group. Interestingly, even after 23 cases from the preliminary set of the VAE-NT group were reclassified into the keratoconus group due to the above criteria, some cases from the VAE-NT group were still found to have suspicious curvature maps (Figure 1).

The current study included 94 eyes that reached objective criteria for normal corneal topography from patients with clinical ectasia in the fellow eye. This constitutes one of the largest cohort studies including such a special group of cases. ${ }^{22,35-37}$ The TBI was sensitive to detect abnormalities among $90.4 \%$ of cases in the VAE-NT group with less than $5 \%$ false-positive results. However, although these cases have been referred to as forme fruste keratoconus by Klyce, ${ }^{38}$ it is important to consider that some of these cases may be true unilateral ectasia cases. ${ }^{39}$ Remarkably, there is an opinion that true unilateral keratoconus does not exist, but also that secondary induced ectasia caused by a pure mechanical process, such as eye rubbing, may occur unilaterally. ${ }^{8}$ These ideas are in agreement with the two-hit hypothesis, which put forward the concept that ectasia results from an underlying genetic predisposition along with external environmental factors, including eye rubbing and atopy. ${ }^{7}$ Our hypothesis is that the TBI may reflect the inherent susceptibility of the cornea to ectasia progression.

A possible study for assessing ectasia susceptibility involves the analysis of the preoperative state of cases that developed ectasia after laser vision correction along with the surgical parameters that represent the impact from surgery on the cornea. ${ }^{40}$ Another possible approach is to integrate finite element simulations with the corneal structural and shape analysis. In addition, adding longitudinal analysis for a retrospective evaluation of patients who progressed to clinical ectasia would further improve criteria to define such a group. ${ }^{10}$ Although we included a relatively large number of cases with mild ectatic corneal disease, $50 \%$ of the cases from the keratoconus and VAE-E groups 
had a Kmax value lower than $52.00 \mathrm{D}$ and $65 \%$ had topometric classification for keratoconus of grade 2 or lower.

A limitation of the current cohort may be the criteria for inclusion in the normal group. Although this is expected to be relatively rare, it is possible that some eyes with a normal clinical examination (including corneal topography and tomography) have mild or susceptible forms of ectasia such as in cases that progressed to keratectasia after different laser vision correction procedures..$^{27,41-44}$ The preoperative state of stable cases with long-term follow-up after laser vision correction would provide a more robust population for the normal group. ${ }^{18,35,40}$

Although different artificial intelligence methods are available, the random fores $\mathrm{t}^{27}$ method provided the most efficient strategy for developing the TBI. As for any machine learning method, it is fundamental to include a cross-validation method to infer or presume external validity of the model. In the current study, the LOOCV was chosen. The LOOCV method increases computational time and complexity, but also significantly increases the reliability or robustness of the model in classifying new data. Interestingly, TBI accuracy, as presented in Figure 2D and Figure 3, refers to the output values from the LOOCV strategy. This is indeed a slightly pessimistic performance compared to the virtually perfect accuracy that would have been found with the 'final' TBI model that is programmed in the commercial Oculus software. Nevertheless, the result from the LOOCV outputs is essentially a more conservative and, theoretically, a more truthful representation of the generalized performance for the TBI in a novel population. However, this is a fundamental consideration that should be addressed in future studies for external validation of TBI, which are already underway.

The TBI is a combined parameter based on Scheimpflug-based corneal tomography and biomechanical assessments. It was accurate for detecting ectasia compared to other topometric, tomographic, and biomechanical parameters, with high sensitivity for detecting subclinical (fruste) ectasia among eyes with normal topography in patients with very asymmetric ectasia.

\section{AUTHOR CONTRIBUTIONS}

Study concept and design (RA, PV); data collection (RA, BTL, $M Q S)$; analysis and interpretation of data (RA, BTL, FF-C, JB, CJR, $A E, R V, P V)$; writing the manuscript (RA, BTL); critical revision of the manuscript ( $B T L, F F-C, M Q S$, JB, CJR, $A E, R V, P V$ ); statistical expertise (RA, BTL, JB); administrative, technical, or material support (RA); supervision (RA)

\section{REFERENCES}

1. Binder PS, Lindstrom RL, Stulting RD, et al. Keratoconus and corneal ectasia after LASIK. J Refract Surg. 2005;21:749-752.

2. Ambrósio R Jr, Randleman JB. Screening for ectasia risk: what are we screening for and how should we screen for it? J Refract Surg. 2013;29:230-232.

3. Santhiago MR, Smadja D, Wilson SE, Krueger RR, Monteiro ML, Randleman JB. Role of percent tissue altered on ectasia after LASIK in eyes with suspicious topography. J Refract Surg. 2015;31:258-265.

4. Santhiago MR, Smadja D, Gomes BF, et al. Association between the percent tissue altered and post-laser in situ keratomileusis ectasia in eyes with normal preoperative topography. Am J Ophthalmol. 2014;158:87-95.

5. Ambrósio R Jr, Dawson DG, Belin MW. Association between the percent tissue altered and post-laser in situ keratomileusis ectasia in eyes with normal preoperative topography. Am J Ophthalmol. 2014;158:1358-1359.

6. Ambrósio R Jr, Wilson SE. Complications of laser in situ keratomileusis: etiology, prevention, and treatment. J Refract Surg. 2001;17:350-79.

7. McGhee CN, Kim BZ, Wilson PJ. Contemporary treatment paradigms in keratoconus. Cornea. 2015;34(suppl 10):S16-S23.

8. Gomes JA, Tan D, Rapuano CJ, et al. Global consensus on keratoconus and ectatic diseases. Cornea. 2015;34:359-369.

9. Ambrósio R Jr, Dawson DG, Salomão M, Guerra FP, Caiado AL, Belin MW. Corneal ectasia after LASIK despite low preoperative risk: tomographic and biomechanical findings in the unoperated, stable, fellow eye. J Refract Surg. 2010;26:906-911.

10. Ambrósio R Jr, Nogueira LP, Caldas DL, et al. Evaluation of corneal shape and biomechanics before LASIK. Int Ophthalmol Clin. 2011;51:11-38

11. Roberts CJ, Dupps WJ Jr. Biomechanics of corneal ectasia and biomechanical treatments. J Cataract Refract Surg. 2014;40:991-998.

12. Ambrósio R Jr, Ramos I, Luz A, et al. Dynamic ultra high speed Scheimpflug imaging for assessing corneal biomechanical properties. Rev Bras Oftalmol. 2013;72:99-102.

13. Huseynova T, Waring GO 4th, Roberts C, Krueger RR, Tomita M. Corneal biomechanics as a function of intraocular pressure and pachymetry by dynamic infrared signal and Scheimpflug imaging analysis in normal eyes. Am J Ophthalmol. 2014;157:885893

14. Vinciguerra R, Elsheikh A, Roberts CJ, et al. Influence of pachymetry and intraocular pressure on dynamic corneal response parameters in healthy patients. J Refract Surg. 2016;32:550-561.

15. Ali NQ, Patel DV, McGhee CN. Biomechanical responses of healthy and keratoconic corneas measured using a noncontact Scheimpflug-based tonometer. Invest Ophthalmol Vis Sci. 2014;55:3651-3659.

16. Bak-Nielsen S, Pedersen IB, Ivarsen A, Hjortdal J. Dynamic Scheimpflug-based assessment of keratoconus and the effects of corneal cross-linking. J Refract Surg. 2014;30:408-414

17. Steinberg J, Katz T, Lucke K, Frings A, Druchkiv V, Linke SJ. Screening for keratoconus with new dynamic biomechanical in vivo scheimpflug analyses. Cornea. 2015;34:1404-1412.

18. Ambrósio R Jr, Lopes B, Faria-Correia F, et al. Ectasia detection by the assessment of corneal biomechanics. Cornea. 2016;35:e18e20.

19. Lopes BT, Ramos IC, Salomão MQ, Canedo ALC, Ambrósio R Jr. Perfil paquimétrico horizontal para a detecção do ceratocone. Rev Bras Oftalmol. 2015;74:382-385. 
20. Vinciguerra R, Ambrósio R Jr, Elsheikh A, et al. Detection of keratoconus with a new biomechanical index. J Refract Surg. 2016;32:803-810.

21. Joda AA, Shervin MM, Kook D, Elsheikh A. Development and validation of a correction equation for Corvis tonometry. Comput Methods Biomech Biomed Engin. 2016;19:943-953.

22. Ambrósio R Jr, Valbon BF, Faria-Correia F, Ramos I, Luz A. Scheimpflug imaging for laser refractive surgery. Curr Opin Ophthalmol. 2013;24:310-320.

23. Lopes B, Ramos ICdO, Ribeiro G, et al. Bioestatísticas: conceitos fundamentais e aplicações práticas. Rev Bras Oftalmol 2014;73:16-22.

24. Rabinowitz YS. Keratoconus. Surv Ophthalmol. 1998;42:297319.

25. Rabinowitz YS, Rasheed K. KISA\% index: a quantitative videokeratography algorithm embodying minimal topographic criteria for diagnosing keratoconus. J Cataract Refract Surg. 1999;25:1327-1335. Erratum in: J Cataract Refract Surg. 2000;26:480.

26. Ramos IC, Correa R, Guerra FP, et al. Variability of subjective classifications of corneal topography maps from LASIK candidates. J Refract Surg. 2013;29:770-775.

27. Breiman L. Random forests. Machine Learning. 2001;45:5-32.

28. Ambrósio R Jr, Luz A, Lopes B, Ramos I, Belin MW. Enhanced ectasia screening: the need for advanced and objective data. $J$ Refract Surg. 2014;30:151-152.

29. Ambrósio R Jr, Ramos I, Lopes B, et al. Ectasia susceptibility before laser vision correction. JCataract Refract Surg. 2015;41:13351336.

30. Belin MW, Ambrósio R. Scheimpflug imaging for keratoconus and ectatic disease. Indian J Ophthalmol. 2013;61:401-406.

31. Belin MW, Villavicencio OF, Ambrósio R Jr. Tomographic parameters for the detection of keratoconus: suggestions for screening and treatment parameters. Eye Contact Lens. 2014;40:326-330.

32. DeLong ER, DeLong DM, Clarke-Pearson DL. Comparing the areas under two or more correlated receiver operating characteristic curves: a nonparametric approach. Biometrics. 1988;44:837845.
33. Bühren J, Kühne C, Kohnen T. Defining subclinical keratoconus using corneal first-surface higher-order aberrations. Am J Ophthalmol. 2007;143:381-389.

34. Marcella Q, Salomão FPG, Ramos IC, et al. Accuracy of topometric indices for distinguishing between keratoconic and normal corneas. International Journal of Keratoconus and Ectatic Corneal Diseases. 2013;2:108-112.

35. Saad A, Gatinel D. Topographic and tomographic properties of forme fruste keratoconus corneas. Invest Ophthalmol Vis Sci. 2010;51:5546-5555.

36. Smadja D, Touboul D, Cohen A, et al. Detection of subclinical keratoconus using an automated decision tree classification. Am J Ophthalmol. 2013;156:237-246.

37. Arbelaez MC, Versaci F, Vestri G, Barboni P, Savini G. Use of a support vector machine for keratoconus and subclinical keratoconus detection by topographic and tomographic data. Ophthalmology. 2012;119:2231-2238.

38. Klyce SD. Chasing the suspect: keratoconus. Br J Ophthalmol. 2009;93:845-847.

39. Ramos IC, Reinstein DZ, Archer TJ, et al. Unilateral ectasia characterized by advanced diagnostic tests. International Journal of Keratoconus and Ectatic Corneal Diseases. 2016;5:51.

40. Ambrósio R Jr, Ramos I, Lopes B, et al. Assessing ectasia susceptibility prior to LASIK: the role of age and residual stromal bed (RSB) in conjunction to Belin-Ambrósio deviation index (BAD-D). Rev Bras Oftalmol. 2014;73:75-80.

41. Klein SR, Epstein RJ, Randleman JB, Stulting RD. Corneal ectasia after laser in situ keratomileusis in patients without apparent preoperative risk factors. Cornea. 2006;25:388-403.

42. Chan CC, Hodge C, Sutton G. External analysis of the Randleman Ectasia Risk Factor Score System: a review of 36 cases of post LASIK ectasia. Clin Experiment Ophthalmol. 2010;38:335-340.

43. Malecaze F, Coullet J, Calvas P, Fournie P, Arne JL, Brodaty C. Corneal ectasia after photorefractive keratectomy for low myopia. Ophthalmology. 2006;113:742-746.

44. Sachdev G, Sachdev MS, Sachdev R, Gupta H. Unilateral corneal ectasia following small-incision lenticule extraction. $J$ Cataract Refract Surg. 2015;41:2014-2018. 


\begin{tabular}{|c|c|c|c|c|}
\hline \multicolumn{5}{|c|}{$\begin{array}{c}\text { TABLE A } \\
\text { Descriptive Statistics }\end{array}$} \\
\hline Parameter & Normal $(n=480)$ & $K C(n=204)$ & VAE-E $(n=72)$ & VAE-NT $(n=94)$ \\
\hline I-S Value & $\begin{array}{c}0.16 \pm 0.55 \\
0.16(-1.46 \text { to } 1.91)\end{array}$ & $\begin{array}{c}5.79 \pm 4.32 \\
4.80(-2.60 \text { to } 33.69)\end{array}$ & $\begin{array}{c}5.17 \pm 3.63 \\
4.34(-2.07 \text { to } 16.07)\end{array}$ & $\begin{array}{c}0.53 \pm 0.51 \\
0.61(-0.76 \text { to } 1.42)\end{array}$ \\
\hline $\mathrm{KISA} \%$ & $\begin{array}{c}10.73 \pm 13.95 \\
5.24(0.33 \text { to } 82.62)\end{array}$ & $\begin{array}{l}2,699.29 \pm 12,870.32 \\
369.72(2.30 \text { to } 173,021)\end{array}$ & $\begin{array}{l}1,579.36 \pm 4,666.63 \\
285.03(2.79 \text { to } 35,153)\end{array}$ & $\begin{array}{c}13.81 \pm 14.88 \\
7.51(0.33 \text { to } 59.20)\end{array}$ \\
\hline Pachy Min & $\begin{array}{l}552.56 \pm 29.99 \\
553(467 \text { to } 646)\end{array}$ & $\begin{array}{c}466.86 \pm 47.84 \\
468.50(173 \text { to } 596)\end{array}$ & $\begin{array}{c}480.11 \pm 42.14 \\
479.50(351 \text { to } 581)\end{array}$ & $\begin{array}{c}517.66 \pm 30.95 \\
521(449 \text { to } 599)\end{array}$ \\
\hline Pachy Apex & $\begin{array}{l}558.45 \pm 30.10 \\
559(470 \text { to } 647)\end{array}$ & $\begin{array}{l}488.60 \pm 123.24 \\
485(209 \text { to } 213)\end{array}$ & $\begin{array}{c}493.85 \pm 43.37 \\
492.50 \text { (356 to } 583)\end{array}$ & $\begin{array}{l}525.98 \pm 29.68 \\
529(451 \text { to } 606)\end{array}$ \\
\hline ART Max & $\begin{array}{l}469.84 \pm 76.56 \\
463(247 \text { to } 744)\end{array}$ & $\begin{array}{c}177.63 \pm 76.08 \\
166.50(0.00 \text { to } 460)\end{array}$ & $\begin{array}{l}197.58 \pm 88.84 \\
174(66.00 \text { to } 442)\end{array}$ & $\begin{array}{l}369.89 \pm 77.23 \\
365(190 \text { to } 546)\end{array}$ \\
\hline ART Avg & $\begin{array}{c}601.90 \pm 93.58 \\
591.50(359 \text { to } 985)\end{array}$ & $\begin{array}{l}261.34 \pm 104.37 \\
259.50(0.00 \text { to } 653)\end{array}$ & $\begin{array}{l}292.61 \pm 110.97 \\
270.50 \text { (101 to } 609)\end{array}$ & $\begin{array}{l}491.43 \pm 78.47 \\
487.5(298 \text { to } 667)\end{array}$ \\
\hline EleF BFS8mmThinnest & $\begin{array}{c}1.90 \pm 1.63 \\
2.00(-4.00 \text { to } 8.00)\end{array}$ & $\begin{array}{c}19.60 \pm 19.33 \\
16.50(-50.00 \text { to } 72.00)\end{array}$ & $\begin{array}{c}19.00 \pm 10.46 \\
16.50(0.00 \text { to } 49.00)\end{array}$ & $\begin{array}{c}2.83 \pm 1.74 \\
3.00(-2.00 \text { to } 9.00)\end{array}$ \\
\hline EleB BFS8mmThinnest & $\begin{array}{c}6.04 \pm 4.40 \\
6.00(-5.00 \text { to } 19.00)\end{array}$ & $\begin{array}{c}56.04 \pm 125.78 \\
42.00(2.00 \text { to } 1,805.00)\end{array}$ & $\begin{array}{c}44.47 \pm 20.86 \\
43.00(12.00 \text { to } 95.00)\end{array}$ & $\begin{array}{c}9.39 \pm 5.21 \\
9.00(1.00 \text { to } 27.00)\end{array}$ \\
\hline SP_A1 & $\begin{array}{c}106.30 \pm 17.65 \\
104.81(60.69 \text { to } 165.00)\end{array}$ & $\begin{array}{c}66.84 \pm 24.11 ; \\
66.72(2.91 \text { to } 150.11)\end{array}$ & $\begin{array}{c}67.25 \pm 24.90 \\
65.66(32.33 \text { to } 116.74)\end{array}$ & $\begin{array}{c}85.19 \pm 26.04 \\
89.29(35.22 \text { to } 142.45)\end{array}$ \\
\hline DARatioMax $2 \mathrm{~mm}$ & $\begin{array}{c}4.30 \pm 0.50 \\
4.30(3.19 \text { to } 5.60)\end{array}$ & $\begin{array}{c}5.86 \pm 1.56 \\
5.58(3.20 \text { to } 15.36)\end{array}$ & $\begin{array}{c}5.53 \pm 1.21 \\
5.33(3.55 \text { to } 8.77)\end{array}$ & $\begin{array}{c}4.83 \pm 0.64 ; \\
4.71 \text { (3.68 to } 6.52)\end{array}$ \\
\hline MaxInverse Radius & $\begin{array}{c}0.16 \pm 0.02 \\
0.15(0.08 \text { to } 0.24)\end{array}$ & $\begin{array}{c}0.21 \pm 0.05 \\
0.20(0.12 \text { to } 0.51)\end{array}$ & $\begin{array}{c}0.20 \pm 0.04 \\
0.19(0.12 \text { to } 0.31)\end{array}$ & $\begin{array}{c}0.17 \pm 0.02 \\
0.17(0.12 \text { to } 0.28)\end{array}$ \\
\hline BAD-D & $\begin{array}{c}0.75 \pm 0.56 \\
0.80(1.13 \text { to } 2.35)\end{array}$ & $\begin{array}{c}7.97 \pm 4.66 \\
6.93(0.76 \text { to } 25.94)\end{array}$ & $\begin{array}{c}6.97 \pm 3.64 \\
6.37(1.82 \text { to } 18.79)\end{array}$ & $\begin{array}{c}1.61 \pm 0.68 \\
1.53(0.18 \text { to } 3.22)\end{array}$ \\
\hline BAD-DI & $\begin{array}{c}0.12 \pm 0.14 \\
0.00(0.070 \text { to } 0.87)\end{array}$ & $\begin{array}{c}0.98 \pm 0.11 ; \\
1.00(0.06 \text { to } 1.00)\end{array}$ & $\begin{array}{c}0.99 \pm 0.06 \\
1.00(0.59 \text { to } 1.00)\end{array}$ & $\begin{array}{c}0.44 \pm 0.31 \\
0.38 \text { (0.01 to } 0.99)\end{array}$ \\
\hline $\mathrm{CBI}$ & $\begin{array}{c}0.06 \pm 0.14 \\
0.00(0.00 \text { to } 0.88)\end{array}$ & $\begin{array}{c}0.92 \pm 0.22 ; \\
1.00(0.00 \text { to } 1.00)\end{array}$ & $\begin{array}{c}0.91 \pm 0.24 \\
1.00(0.00 \text { to } 1.00)\end{array}$ & $\begin{array}{c}0.41 \pm 0.40 \\
0.24 \text { (0.00 to } 1.00)\end{array}$ \\
\hline LRAI & $\begin{array}{c}0.11 \pm 0.15 \\
0.00(0.50 \pm 0.79)\end{array}$ & $\begin{array}{c}0.88 \pm 0.26 \\
1.00(0.03 \text { to } 1.00)\end{array}$ & $\begin{array}{c}0.81 \pm 0.33 \\
1.00(0.02 \text { to } 1.00)\end{array}$ & $\begin{array}{c}0.87 \pm 0.28 \\
1.00(0.02 \text { to } 1.00)\end{array}$ \\
\hline SVMI & $\begin{array}{c}0.10 \pm 0.11 \\
0.08(0.04 \text { to } 0.95)\end{array}$ & $\begin{array}{c}0.88 \pm 0.28 \\
1.00(0.07 \text { to } 1.00)\end{array}$ & $\begin{array}{c}0.81 \pm 0.35 \\
1.00(0.05 \text { to } 1.00)\end{array}$ & $\begin{array}{c}0.88 \pm 0.30 \\
1.00(0.04 \text { to } 1.00)\end{array}$ \\
\hline TBI & $\begin{array}{c}0.07 \pm 0.10 \\
0.00(0.07 \text { to } 0.75)\end{array}$ & $\begin{array}{c}0.97 \pm 0.04 \\
0.97 \text { (0.83 to } 1.00)\end{array}$ & $\begin{array}{c}0.97 \pm 0.04 \\
0.97(0.87 \text { to } 1.00)\end{array}$ & $\begin{array}{c}0.76 \pm 0.28 \\
0.76(0.08 \text { to } 1.00)\end{array}$ \\
\hline \multicolumn{5}{|c|}{ 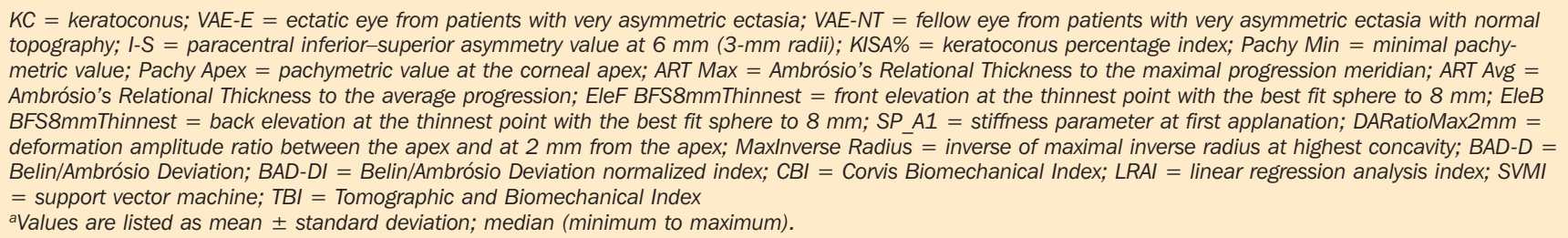 } \\
\hline
\end{tabular}




\begin{tabular}{|c|c|c|c|c|c|c|c|}
\hline \multicolumn{8}{|c|}{$\begin{array}{c}\text { TABLE } B \\
\text { Results of ROC Curve Analysis }\end{array}$} \\
\hline Parameter & AUROC & Sensitivity & Specificity & $\begin{array}{c}\text { Correctly } \\
\text { Classified (\%) }\end{array}$ & Cut-off & $\begin{array}{c}\text { Specificity @ } \\
\text { 100\% Sensitivity }\end{array}$ & AUSEP \\
\hline \multicolumn{8}{|c|}{ Normal vs KC, VAE-E, and VAE-NT } \\
\hline BAD-D & 0.956 & 0.841 & 0.965 & 90.3 & 1.62 & 14 & 51 \\
\hline BAD-DI & 0.956 & 0.841 & 0.965 & 90.3 & 0.45 & 14 & 83 \\
\hline $\mathrm{CBI}$ & 0.937 & 0.808 & 0.971 & 88.9 & 0.46 & 0 & 82 \\
\hline LRAI & 0.967 & 0.884 & 0.960 & 92.2 & 0.44 & 31 & 95 \\
\hline SVMI & 0.964 & 0.868 & 0.975 & 92.1 & 0.34 & 1 & 105 \\
\hline TBI & 0.996 & 0.962 & 0.988 & 97.5 & 0.48 & 72 & 110 \\
\hline \multicolumn{8}{|c|}{ Normal vs $\mathrm{KC}$ and VAE-E } \\
\hline BAD-D & 0.997 & 0.982 & 0.992 & 98.7 & 1.97 & 47.3 & 64 \\
\hline BAD-DI & 0.997 & 0.982 & 0.992 & 98.7 & 0.69 & 47.3 & 95 \\
\hline $\mathrm{CBI}$ & 0.977 & 0.946 & 0.975 & 96.0 & 0.49 & 12.9 & 95 \\
\hline LRAI & 0.967 & 0.888 & 0.960 & 92.4 & 0.44 & 32 & 99 \\
\hline SVMI & 0.964 & 0.877 & 0.967 & 92.2 & 0.30 & 1 & 109 \\
\hline TBI & 1.000 & 1.000 & 1.000 & 100 & 0.79 & 100 & 112 \\
\hline \multicolumn{8}{|c|}{ Normal vs VAE-NT } \\
\hline BAD-D & 0.838 & 0.809 & 0.717 & 76.3 & 1.08 & 14 & 49 \\
\hline BAD-DI & 0.838 & 0.809 & 0.717 & 76.3 & 0.14 & 14 & 47 \\
\hline $\mathrm{CBI}$ & 0.822 & 0.681 & 0.823 & 75.2 & 0.07 & 0 & 46 \\
\hline LRAI & 0.968 & 0.872 & 0.969 & 92.1 & 0.51 & 31 & 125 \\
\hline SVMI & 0.965 & 0.851 & 1.000 & 92.6 & 0.96 & 1 & 79 \\
\hline TBI & 0.985 & 0.904 & 0.960 & 93.2 & 0.29 & 71.9 & 99 \\
\hline \multicolumn{8}{|c|}{$\begin{array}{l}R O C=\text { receiver operating characteristic; } A U R O C=\text { area under the ROC curve; AUSEP = area under the separation curve; } K C=\text { keratoconus; VAE-E = ectatic eye } \\
\text { from patients with very asymmetric ectasia; } V A E-N T=\text { fellow eye from patients with very asymmetric ectasia with normal topography; BAD-D = Belin/Ambrósio } \\
\text { Deviation value; } B A D-D I=\text { Belin/Ambrósio Deviation normalized index; } C B I=\text { Corvis Biomechanical Index; } L R A I=\text { linear regression analysis index; SVMI = support } \\
\text { vector machine; } T B I=\text { Tomographic and Biomechanical Index }\end{array}$} \\
\hline
\end{tabular}

